Article - Biological and Applied Sciences

\title{
Microscale direct transesterification of microbial biomass with ethanol for screening of microorganisms by its fatty acid content
}

\author{
Vanessa Ghiggi Sorgatto ${ }^{1}$ \\ orcid.org/0000-0001-8852-5677 \\ Julio Cesar de Carvalho ${ }^{1, *}$ \\ orcid.org/0000-0001-7558-7748 \\ Eduardo Bittencourt Sydney ${ }^{2}$ \\ orcid.org/0000-0001-7194-8315 \\ Adriane Bianchi Pedroni Medeiros ${ }^{1}$ \\ orcid.org/0000-0002-8804-0407 \\ Luciana Porto de Souza Vandenberghe ${ }^{1}$ \\ orcid.org/0000-0003-0267-1185 \\ Carlos Ricardo Soccol ${ }^{1}$ \\ orcid.org/0000-0001-7630-6864 \\ ${ }^{1}$ Bioprocess Engineering and Biotechnology Department, Federal University of Paraná - \\ 81531-980, Curitiba, Brazil \\ ${ }^{2}$ Federal University of Technology - Paraná, Department of Bioprocess Engineering and \\ Biotecnology - 84016-210, Ponta Grossa, Paraná
}

Received: 2018.04.10; Accepted: 2019.02.16.

* Correspondence: jccarvalho@ufpr.br; Tel.: +55-41-33613695 for JCC.

\section{HIGHLIGHTS}

- Direct transesterification in microscale (3mg samples) was developed.

- Seven species from six genera of microrganisms of industrial interest were used

- Ethanol was successfully used as replacement for the traditional methanol $(98 \%$ conversion)

- The method was compared with lipid extraction and macroscale transesterification 
Abstract: We present an improved method of direct transesterification suitable for the quantitative analysis of multiple dry samples for its fatty acid content, using a minimal amount of biomass and reactants. The method features an acid-catalyzed direct alcoholysis of microgram samples of dry biomass; the rationale behind the solvent and reagent proportions chosen is discussed. The method was validated using seven microbial strains with diverse lipid content (Saccharomyces cerevisiae, Saccharomyces boulardii, Candida tropicalis, Haematococcus pluvialis, Chlorella vulgaris, Spirulina platensis and Schizochytrium limacinum), and compared with a macroscale direct transesterification method, and with gravimetric analysis of lipids extracted with solvents. The microscale method showed a conversion of $98.06 \pm 0.87 \%$ of the lipids, using approximately $3 \mathrm{mg}$ of dry biomass, $1 \mathrm{~mL}$ of $0.2 \mathrm{M} \mathrm{H} 2 \mathrm{SO} 4$ dissolved in anhydrous ethanol (the acid is the catalyzer and ethanol the reactant)). The mixture was maintained at $70{ }^{\circ} \mathrm{C}$ for $20 \mathrm{~h}$ with periodic mixing, and then extracted with $2 \mathrm{~mL} n$-heptane and analyzed by GC-FID. The lipid content was then calculated considering dilution and sample mass. This method is effective, reliable, and technically attractive for analytical and comparative purposes.

Keywords: microbial oil; ethanolysis; FAEE; microscale; screening.

\section{INTRODUCTION}

Novel lipid sources for bioenergy and dietary uses are in demand. There is a large variety of industrial lipid sources, including vegetable oils, animal fats and waste grease, all of which are composed mostly of TAGs (triacylglycerols, glycerin esters of fatty acids). At this time, refined vegetable oils are the main feedstock for food and also biodiesel production [1,2]. However, a sustainable biodiesel industry requires alternative TAG feedstocks obtainable through other routes, especially those that can be continuously produced without extensive land requirements. Thus, over the past two decades, there have been extensive studies on the feasibility of lipid production from microbial sources for sustainable biodiesel applications [3,4].

On the other side, microbial sources of dietary lipids such as Mortierella alpina (for arachidonic acid) and Schizochytrium limacinum (for docosahexaenoic acid) are currently used to produce nutraceuticals and infant formulas, and the market for these "microbial oils" is growing. These microorganisms are capable of rapid growth and high productivity compared to other sources of lipids $[4,5,6]$. Because the identification of high-yield strains is a useful indicator of the potential costs of biodiesel production, the selection of appropriate strains is a crucial step for a successful and economically viable production of dietary lipids and biofuels from microbial sources [7]. This type of research requires an analysis of many samples and culture conditions. Thus, small-scale, simple and reliable methods for the determination of fatty acid content are desired.

The transesterification (alcoholysis) of TAG, or the esterification of free fatty acids (FFA) is used both to make biofuels and to analyze the lipid composition of fats and oils. The process is a reversible reaction in which oils or fats react with a low molecular weight alcohol in the presence of a catalyst (usually a strong acid or base) to yield the corresponding mono-alkyl esters (biodiesel) and glycerol as a by-product $[5,8]$. Generally, methanolysis is considered more economic in comparison to ethanolysis, but for those countries where production is large (EUA, Brazil, India, China and Colombia) the use of ethanol in the transesterification of oils to produce biodiesel appears as an alternative. Moreover, the use of ethanol presents environmental advantages [9] and a slight increase in the heat content and the cetane number [10].

The conventional transesterification reaction of a biomass involves a two-step process: lipid extraction from the biomass followed by its conversion into the alkyl esters of fatty acids $[3,11]$. Because these steps require many manipulations, large numbers of samples are slow to process in the laboratory. However, a few procedures utilizing a one-step in-situ 
transesterification to avoid the initial time-consuming oil extraction step have been investigated [12-14]. Several of these studies were developed for biodiesel production, but direct transesterification can also be used for one-pot extraction and derivatization of lipids for posterior chromatographic analysis.

Because the conventional two-step transesterification process is time-consuming and requires a relatively large amount of biomass, the screening of several strains or culture conditions using indirect transesterification requires the use of large amounts of space and reagents. A simple and rapid quantitative determination of biomass fatty acids is very important for the study of lipid production by genetically engineered microorganisms.

This paper describes a microscale method for analytical purposes suitable as a screening step for determining promising oleaginous microorganisms or for the comparison of culture conditions. The proposed method is a one-pot direct microscale transesterification process based on previous direct transesterification methods, and provides a simpler and promising fatty acid analysis tool applicable for the rapid throughput processing of many samples.

\section{MATERIAL AND METHODS}

\section{Strains and cultivation}

The lipid content of seven microorganisms was evaluated using direct transesterification procedures on dry biomass. These microorganisms were:

Yeasts: Saccharomyces cerevisiae (lyophilized Fleischmann ${ }^{\circledR}$ baker's yeast), Saccharomyces boulardii (ATCC® MYA-796TM) and Candida tropicalis (ATCC® 750TM), all cultured in YPD medium (10.0 g yeast extract, $20.0 \mathrm{~g}$ peptone, $20.0 \mathrm{~g}$ dextrose, and $1 \mathrm{~L}$ distilled water adjusted to a final $\mathrm{pH}$ of 5.6);

Microalgae: Haematococcus pluvialis (SAG® $34-1 \mathrm{~b}$ ) and Chlorella vulgaris (SAG® 2.80), cultured in ES Basal Medium ( $0.2 \mathrm{~g} \mathrm{KNO}_{3}, 0.02 \mathrm{~g} \mathrm{~K}_{2} \mathrm{HPO}_{4}, 0.02 \mathrm{~g} \mathrm{MgSO} 4.7 \mathrm{H}_{2} \mathrm{O}, 0.03$ $\mathrm{mL}$ soil extract, $5 \mathrm{~mL}$ micronutrient solution and $995 \mathrm{~mL}$ distilled water) and Spirulina platensis (SAG® 21.99), cultured in Spirul Medium (13.61 $\mathrm{g} \mathrm{NaHCO}_{3}, 4.03 \mathrm{~g} \mathrm{Na}_{2} \mathrm{CO}_{3}, 2.5 \mathrm{~g}$ $\mathrm{NaNO}_{3}, 0.5 \mathrm{~g} \mathrm{~K}_{2} \mathrm{HPO}_{4}, 1.0 \mathrm{~g} \mathrm{~K}_{2} \mathrm{SO}_{4}, 1.0 \mathrm{~g} \mathrm{NaCl}, 0.04 \mathrm{~g} \mathrm{CaCl}_{2} .2 \mathrm{H}_{2} \mathrm{O}, 0.08 \mathrm{~g} \mathrm{Na}_{2} \mathrm{EDTA}, 0.2 \mathrm{~g}$ $\mathrm{MgSO}_{4} \cdot 7 \mathrm{H}_{2} \mathrm{O}, 0.01 \mathrm{~g} \mathrm{FeSO} \cdot 7 \mathrm{H}_{2} \mathrm{O}, 5.0 \mathrm{~mL}$ micronutrient solution, and $995 \mathrm{~mL}$ distilled water). The micronutrient solution composition is $1 \mathrm{mg} \mathrm{ZnSO}_{4} .7 \mathrm{H}_{2} \mathrm{O}, 2 \mathrm{mg} \mathrm{MnSO} \mathrm{M}_{4} .4 \mathrm{H}_{2} \mathrm{O}, 10$ $\mathrm{mg} \mathrm{H}_{3} \mathrm{BO}_{3}, 1 \mathrm{mg} \mathrm{Co}\left(\mathrm{NO}_{3}\right)_{2} \cdot 6 \mathrm{H}_{2} \mathrm{O}, 1 \mathrm{mg} \mathrm{Na} \mathrm{MoO}_{4} .2 \mathrm{H}_{2} \mathrm{O}, 0.05 \mathrm{mg} \mathrm{CuSO} \mathrm{CH}_{4} .5 \mathrm{H}_{2} \mathrm{O}, 700 \mathrm{mg}$ $\mathrm{FeSO}_{4} .7 \mathrm{H}_{2} \mathrm{O}$ and $800 \mathrm{mg}$ EDTA dissolved in $1 \mathrm{~L}$ of distilled water. Media $\mathrm{pH}$ was not adjusted.

The labyrinthulomycete Schizochytrium limacinum (ATCC® MYA-1381TM), cultured in $\mathrm{By}+$ Medium (1.0 g yeast extract, $1.0 \mathrm{~g}$ peptone, $5.0 \mathrm{~g}$ dextrose and $1 \mathrm{~L}$ seawater with no adjustment of the final $\mathrm{pH}$ ).

All culture media were sterilized at $121^{\circ} \mathrm{C}$ and $1 \mathrm{~atm}$ for $20 \mathrm{~min}$.

The strains were obtained from American Type Culture Collection (Manassas, USA) and Sammlung von Algenkulturen Göttingen Culture Collection of Algae (Gottingen, DE). All cultures were performed in $5 \mathrm{~L}$ Erlenmeyer flasks with a $3.0 \mathrm{~L}$ working volume for each medium and $10 \%(\mathrm{v} / \mathrm{v})$ inoculum. The microalgae strains were cultured for 15 days at $25 \pm$ $1^{\circ} \mathrm{C}$ on a $12: 12 \mathrm{~h}$ light:dark cycles with a light irradiation of $34 \mu \mathrm{mol}$ photons $\mathrm{m}^{-2} . \mathrm{s}^{-1}$ from white fluorescent lamp lights. The yeast cultures were incubated for $48 \mathrm{~h}$ at $27 \pm 1^{\circ} \mathrm{C}$, and Schizochytrium limacinum cultivation was performed for 7 days at $25 \pm 1{ }^{\circ} \mathrm{C}$.

After cultivation, the cells were harvested by centrifugation at $4000 \mathrm{~g}$ for $10 \mathrm{~min}$ and washed twice with distilled water. The recovered pellets were dried in a vacuum oven at $45^{\circ} \mathrm{C}$ to a constant weight.

\section{Lipid Extraction}

For each species, the lipid content was expressed as a percentage of total mass. The oil content of each biomass was determined using gravimetric methods. Samples of $1.0 \mathrm{~g}$ of dry biomass were settled in a cellulose cartridge and extracted for $4 \mathrm{~h}$ at $70{ }^{\circ} \mathrm{C}$ in a Soxhlet 
apparatus with $100 \mathrm{~mL}$-hexane (Merck, Germany). After the extraction, the solvent was recycled, and the lipid fraction was dried to a constant weight in an oven at $40^{\circ} \mathrm{C}$.

\section{Direct Transesterification of Microbial Biomass}

Preliminary experiments were conducted (data not shown) using direct transesterification methods described in the literature [13,15-17]. The protocol reported by Liu and Zhao [15] was selected as a reference method for the development of alternative protocols and for comparisons of conversion yields.

A few adaptations of the reference direct transesterification method[15] were done, based also in other transesterification reports: the original method uses $1000 \mathrm{mg}$ of biomass mixed with $20 \mathrm{~mL}$ of $0.2 \mathrm{M} \mathrm{H}_{2} \mathrm{SO}_{4}$ or $\mathrm{HCl}$ in methanol, reacting for $20 \mathrm{~h}$ at $70^{\circ} \mathrm{C}$. We reduced sample mass to $0.1 \mathrm{~g}$ and substituted methanol by the less toxic, less volatile and less polar ethanol. Also, to guarantee that the ethanol was anhydrous, the mineral acid solution was dried over saturated anhydrous sodium sulfate prior to reaction. The reaction was done with maintaining proportion: $0.1 \mathrm{~g}$ of dried biomass with a biomass-to-ethanol ratio of $1: 20(\mathrm{w} / \mathrm{v})$, or $2 \mathrm{~mL}$ of $0.2 \mathrm{M} \mathrm{H}_{2} \mathrm{SO}_{4}$. The reaction was performed in closed $10 \mathrm{~mL}$ vials in a covered bath, heated to $70^{\circ} \mathrm{C}$ and periodically vortexed ( 3 min agitation every $4 \mathrm{~h}$ ). After $20 \mathrm{~h}$ of reaction, the suspension was cooled and $4 \mathrm{~mL}$ of organic extracting solvent (n-heptane) was added. Following extraction, the organic layer was separated and dried over anhydrous sodium sulfate. The samples were collected and stored in vials to be analyzed using a Shimadzu GC-2010 system (Shimadzu Scientific Instruments, Columbia, MD). The biomass lipid content (BLC) is calculated from the lipid concentration in the extract (LCE, in ppm or $\mathrm{mg} / \mathrm{L}$ ) as analyzed by GC-FID using Eq. 1:

$$
\operatorname{BLC}(\%)=0.004 \times \operatorname{LCE} \div \text { BSM }
$$

where BSM is the dry biomass sample mass, in $\mathrm{mg}$

\section{Microscale Direct Transesterification of Microbial Biomass}

Fatty acid ethyl esters (FAEE) were prepared from dried microbial biomass through the direct transesterification biomass using a sample of approximately $3 \mathrm{mg}$ dry weight. The dry biomass samples were mixed with $1 \mathrm{~mL}$ of freshly prepared ethanolic solution containing 0.2 $\mathrm{M} \mathrm{H}_{2} \mathrm{SO}_{4}$, previously dried with anhydrous sodium sulfate. The suspensions were vortexed for $2 \mathrm{~min}$ and heated at $70^{\circ} \mathrm{C}$ for $20 \mathrm{~h}$ in an oven. The acid-catalyzed reaction was done in 4 $\mathrm{mL}$ amber glass vials with cap and septa for gas chromatography, which can withstand the vapor pressure of the mixture, and would leak rather than burst if the event of excessive heating. The samples were periodically vortexed ( $3 \mathrm{~min}$ every $4 \mathrm{~h}$ ). After the reactions were completed, the suspensions were cooled to room temperature and mixed with $1 \mathrm{ml}$ of distilled water to increase the polarity of the ethanolic phase and to dissolve excess acids and glycerol. The fatty acid alkyl ester mixtures were then extracted with $2 \mathrm{~mL}$ of organic solvent ( $n$-heptane), and the two phases were allowed to separate. When ready for analysis, the tubes were centrifuged at $2688 \mathrm{~g}$ for $10 \mathrm{~min}$ to accelerate phase separation. The upper layer, which contained FAEE, was extracted and dehydrated over anhydrous sodium sulfate. The extracts were collected and stored in glass chromatography vials for analysis on a Shimadzu 2010 GC system (Shimadzu Scientific Instruments, Columbia, MD). The biomass lipid content (BLC) was calculated from the lipid concentration in the extract (LCE, in ppm or $\mathrm{mg}^{\mathrm{L}} \mathrm{L}^{-1}$ ) as analyzed by GC-FID using Eq. 2:

$$
\operatorname{BLC}(\%)=0.002 \times \operatorname{LCE} \div \mathrm{BSM}
$$

where BSM is the dry biomass sample mass, in $\mathrm{mg}$.

\section{Fatty Acid Content Analysis}


The fatty acid content analysis was performed via gas chromatography in a Shimadzu GC-2010 system (Shimadzu Scientific Instruments, Columbia, MD) equipped with a split/splitless injector, a flame ionization detector (FID) and an RTX-Wax capillary column (30 $\mathrm{m} \times 0.25 \mathrm{~mm} \times 0.25 \mu \mathrm{m})$ and an automatic injector (AOC-20i). The temperature program: $150^{\circ} \mathrm{C}$ for $3 \mathrm{~min}$; then heating at $10^{\circ} \mathrm{C} / \mathrm{min}$ to $210^{\circ} \mathrm{C}$; maintaining for $15 \mathrm{~min}$; heating at $10^{\circ} \mathrm{C} / \mathrm{min}$ to $240^{\circ} \mathrm{C}$; maintaining for another $10 \mathrm{~min}$. The FID detector was kept at $250^{\circ} \mathrm{C}$ and the automatic injector temperature at $130^{\circ} \mathrm{C}$, the split ratio used was $1: 50$ and hydrogen was used as carrier gas. The peaks were identified by comparison of the retention time of the unknown compounds with FAME (Sigma) standard compounds, and quantified based on their specific areas.

The fatty acids were identified by comparing the retention times with those of standard fatty acids (Supelco 37 FAME mix). The fatty acid contents were quantified by comparing their peak areas with those of the external standards. Ethanol was used in the modified transesterification reaction and was compared with the standard FAME. This method resulted in a slightly higher retention times because a 2-carbon alcohol was used instead of a 1-carbon alcohol; the response of the FID is proportional to concentration, and therefore pooled FAEEs could be determined quantitatively.

\section{Method Evaluation and Comparison}

The microscale direct transesterification method was validated for the determination of fatty acid (FA) content in microbial biomass. The results obtained in the proposed method were compared with the results obtained using the adapted method described by [15], and the TAG conversion yield was estimated relative to the weight of the total lipid content in the dried biomass samples. In the initial trials, to test the efficiency of the operation parameters, such as alcohol dosage, catalyst concentration, reaction temperature and time, a two-step alcoholysis method was mimicked and applied to a pre-extracted oil until a $100 \%$ conversion yield was achieved.

To determine the reproducibility of the proposed method, all samples were individually prepared in triplicate, and the results were statistically analyzed using $R$, version 2.15.2 (Copyright@ 2012, The R Foundation for Statistical Computing). Comparisons between the methods were performed using analysis of variance (ANOVA), and the level of significance was set at $\alpha=0.05$.

\section{DISCUSSION}

\section{Choosing the Reaction Conditions}

It is well known that transesterification of TAG is significantly influenced by several operational parameters, including the oil/biomass to alcohol ratio, the catalyst loading, the reaction time and the temperature and the purity of the reactants [12]. After initial tests with microbial biomass, the following conditions were defined:

\section{Ethanol}

In the in situ transesterification process, alcohols have a vital role, acting as the solvent and extracting the lipids from the biomass, and as the reactant, converting the lipids to fatty acid alkyl esters. The alcohols used in the transesterification reactions include methanol, ethanol, propanol, butanol, and amyl alcohol. Methanol and ethanol are most frequently used in laboratory research and in the biodiesel industry [18,19], and the selection of one of these substances is dependent on costs and performance [20].

Although some authors [16,18] did not observe any differences in direct transesterification reactions when using different alcohols, the use of ethanol as a reactant instead of the more commonly used methanol resulted in a significant increase $(27 \pm 3 \%)$ in the ester conversion yield, as was observed in this study. This may be due to the enhanced homogenization of the reactants and the samples in the presence of ethanol, precluding the need for a constant agitation of the reaction vials. 
Ethanol is less polar than methanol, is thus a better solvent for TAG, and could potentially enhance the simultaneous extraction and conversion of the lipids in the one-step process. In addition, for laboratory research and analytical purposes, ethanol offers advantages because it is safer than methanol and is a bio-based solvent. Compared with methanol, the observed increased in neutral oil solubility in ethanol was consistent with reports [21] on direct transesterification reactions.

"Absolute" ethanol contains low levels of water (0.2\% for ACS grade reagents[22]), and the presence of water could reduce the conversion efficiency. Therefore, ethanol solutions of the previously prepared transesterification solutions were dehydrated by drying over saturated anhydrous sodium sulfate. The decreased water content in the ethanol solutions led to an increased neutral oil solubility in ethanol and drove the equilibrium of the reaction toward ethyl-ester formation [21].

\section{Reagent proportions}

Alcohol loading has also been found to be critical for the acid-promoted transesterification of oil. Transesterification is an equilibrium reaction in which a large excess of alcohol is required to shift the equilibrium toward the substitution of glycerol by the monoalcohol, forming ethyl esters [23] [24].

An optimal yield of $96.8 \%$ was achieved using the reference method [15] in experiments with a 1:16 (w/w) biomass-to-ethanol ratio. The yield decreased to $64 \%$ when the ethanol loading was decreased to $1: 4(\mathrm{w} / \mathrm{w})$. In the experiments performed by Miao and $\mathrm{Wu}$ [20], a $68 \%$ yield was obtained at an oil-to-methanol molar ratio of $1: 45$, and Johnson and Wen [13] reported a very low yield (12.7\%) in the direct transesterification of a $1: 5.8(\mathrm{w} / \mathrm{w})$ biomass-to-methanol solution (without co-solvents).

The microscale method developed used a biomass-to-ethanol ratio of approximately 1:263 (w/w), i.e., an extremely high molar excess of alcohol (but a low overall amount of reagents). This was necessary to reduce handling errors in the microscale method. This large molar ratio of alcohol to biomass probably ensured the acceptable reaction rates [20] and facilitated the dissolution of TAGs in the alcohol phase.

Regarding the amount of catalyst, this work used 15 to 25 times the typical amount of catalyst to accelerate the conversion and benefit from the dehydrating characteristics of sulfuric acid.

Although such conditions are unfavorable for an industrial transesterification process, for laboratory analytical purposes, this use of excess reagents in the microscale method translates into the use of $1 \mathrm{ml}$ of ethanol and $29 \pm 1 \mathrm{mg}$ of acid per sample, thus avoiding the high costs of conventional analyses.

\section{Temperature, time and stirring rate}

These factors strongly helped the esterification process because ethanol is not miscible with triglycerides at ambient temperatures [25]. However, as the temperature increased, the solubility increased until the critical solution temperature was reached, at which point the components became miscible. At and beyond this point, these factors directly influence the contact and solubility of the reactants [26].

A number of previous studies have described transesterification using methanol at or above $60^{\circ} \mathrm{C}[13,15,17]$. This is an efficient approach but requires well-sealed tubes and careful temperature control because the working pressures exceed $120 \mathrm{kPa}$. In this study, ethanol was used in the transesterification reactions at reaction temperatures of $70^{\circ} \mathrm{C}$ and vapor pressures of approximately $73 \mathrm{kPa}$. Under these conditions, regular glass vials may be used, making the procedure safer. If pressurized vials are used, then higher temperatures might be used, the assay time may be further reduced, and the number of samples processed increased. In this study, a $20 \mathrm{~h}$ reaction time was used, which corresponds to the optimized timeframe of the referenced acid-catalyzed transesterification method [15] and because of its convenience, i.e., sample preparation and batch analysis can be performed on consecutive days. 
The reaction mixtures are typically mechanically stirred to enhance mass transfer between the reactants [23]. Previous works have reported using continuous stirring [13-15], because their reactions required long mixing times to reach saturation conditions. With high biomass too solvent ratio (as used in this microscale method) the process probably can rely on mixture by diffusion, after initial mixing at $70^{\circ} \mathrm{C}$. This study used a method based on the periodic mixing of the reactants using a vortexer, in which the vials were shaken for 3 min in $4 \mathrm{~h}$ time intervals.

\section{Phase separation.}

After the addition of water (to dissolve the remaining ethanol and sulfuric acid) and $\mathrm{n}$-heptane (to dissolve FAEE), the final reaction products were separated to two phases. Previous studies have reported that a large excess of alcohol slowed down the phase separation process $[20,23]$ and that the use of ethanol may facilitate the formation of stable emulsions. However, in the proposed method, the addition of water promoted a rapid phase separation and prevented the formation of emulsions.

\section{Catalyst}

Several authors have reported on the direct transesterification of biomass for biodiesel production and for analytical purposes $[16,18]$. The most common methods used involve alkaline catalysis, which is known to achieve a rapid and efficient transesterification of TAG, but may form soaps by neutralizing FFA and saponifying TAG in the presence of residual water. Other methods used acid catalysis, which is slower and requires higher reaction temperatures, but forms fewer by-products and is adequate for biomass rich in FFA [27].

To carry the base-catalyzed reaction to completion, an FFA content lower than $3 \%$ is required. The higher the acidity of the oil, the lower the conversion efficiency becomes [23]. Therefore, an acid catalyst (i.e., sulfuric acid) was used in this study because the oil content in microbial biomass typically includes high levels of free fatty acids [28].

\section{Evaluating the Microscale Transesterification Method}

To verify the suitability of the proposed direct transesterification method, three sets of experiments were performed using the seven dried biomasses ( $S$. cerevisiae, $S$. boulardii, C. tropicalis, $H$. pluvialis, $C$. vulgaris, $S$. platensis and $S$. limacinum). The results from the direct extraction of lipids with n-hexane using a Soxhlet apparatus, the reference method (direct transesterification adapted from [15]) and the microscale direct transesterification (proposed method) are presented in Table 1. Column 2 shows the quite variable lipid content for each kind of biomass - from low lipid (and highly proteic) biomasses such as that of $S$. platensis, to lipid-rich biomasses such as that of S. limacinum. The lipid conversion yield into esters is estimated from the FAEE content divided by the lipid content (determined by solvent extraction) [29].

Table 1. Lipid content and ethyl ester fatty acid (FAEE) content for reference and microscale methods, as \% of lipids in dry biomass, and transesterification yields for both methods. Differences in lines show the wide variability of lipid content in different microbial biomasses. Data is expressed as averages of three replicates \pm standard error)

\begin{tabular}{|c|c|c|c|c|c|}
\hline \multirow[b]{2}{*}{ Microorganism } & \multirow{2}{*}{$\begin{array}{l}\text { Solvent } \\
\text { extraction } \\
\text { (SE) } \\
\text { Lipid } \\
\text { content by } \\
\text { SE (\%) }\end{array}$} & \multicolumn{2}{|c|}{$\begin{array}{l}\text { Reference } \quad \text { direct } \\
\text { transesterification (DT) }\end{array}$} & \multicolumn{2}{|c|}{$\begin{array}{l}\text { Microscale direct } \\
\text { transesterification } \\
\text { (MDT) }\end{array}$} \\
\hline & & $\begin{array}{l}\text { Lipid } \\
\text { content (\%) }\end{array}$ & $\begin{array}{l}\text { Yield \% } \\
\text { (lipid SE } \\
\text { /lipid DT) }\end{array}$ & $\begin{array}{l}\text { Lipid } \\
\text { content (\%) }\end{array}$ & $\begin{array}{l}\text { Yield \% } \\
\text { (lipid } \\
\text { MDT /lipid } \\
\text { DT) }\end{array}$ \\
\hline C. tropicalis & $4.68 \pm 0.03$ & $3.97 \pm 0.09$ & 84.83 & $4.54 \pm 0.04$ & 97.01 \\
\hline S. boulardii & $5.71 \pm 0.06$ & $5.41 \pm 0.22$ & 94.75 & $5.65 \pm 0.05$ & 98.95 \\
\hline S. cerevisiae & $6.17 \pm 0.10$ & $5.64 \pm 0.09$ & 91.41 & $5.97 \pm 0.05$ & 96.76 \\
\hline
\end{tabular}




\begin{tabular}{lccccc} 
C. vulgaris & $7.97 \pm 0.03$ & $7.81 \pm 0.09$ & 97.99 & $7.89 \pm 0.03$ & 99.00 \\
H. pluvialis & $20.76 \pm 0.20$ & $20.26 \pm 0.12$ & 97.59 & $20.43 \pm 0.08$ & 98.41 \\
S. platensis & $4.96 \pm 0.03$ & $4.79 \pm 0.12$ & 96.57 & $4.87 \pm 0.04$ & 98.19 \\
S. limacinum & $24.68 \pm 0.18$ & $23.44 \pm 0.34$ & 94.98 & $24.21 \pm 0.20$ & 98.10 \\
\hline Method average & - & - & 94.01 & - & 98.06 \\
\hline
\end{tabular}

Using the lipid content obtained by extraction as reference (representing $100 \%$ of the lipids), the yields can be estimated for both direct transesterification methods. The reference method showed a conversion of lipids to FAEE of $94.0 \%$, while the microscale direct transesterification method resulted in an average conversion of $98.1 \%$ (these are averages of all ratios of \%FAEE per \% lipid content). Contrary to the findings of a few studies using direct transesterification, the results here showed that the integration of co-solvents, such as chloroform or diethyl ether, to improve the direct transesterification of microbial biomass in the reaction was not necessary for a high yield when using the proposed microscale transesterification method $[12,14]$. Under the same direct transesterification conditions with pre-extracted oil, a $100 \%$ conversion with good homogenization of oil and ethanol was observed.

Significant differences (via ANOVA; $p$-value $=0.001046$ ) were observed between the two procedures for fatty acid conversion (Table 2 ).

Table 2. Analysis of variance (ANOVA) between the treatments

\begin{tabular}{lccccc}
\hline Sources of Variation & DF & SS & MS & F-test & p-value \\
\hline Treatments & 1 & 200.24 & 200.24 & 12.499 & 0.001046 \\
Error & 40 & 640.85 & 16.021 & & \\
Total & 41 & 841.09 & 216.21 & & \\
\hline
\end{tabular}

${ }^{*} \mathrm{SS}=$ sum of squares; DF = degrees of freedom; MS = mean square

The reference method showed a larger deviation (Fig. 1), possibly because larger samples require more agitation. Negligible differences in the fatty acid content estimates were observed between the microalgae strains and in S. limacinum cultures, indicating the likely diffusion of solvent and TAGs in these samples. However, a greater difference was observed with yeast cells, which could be due to the high permeation resistance of the cell walls.

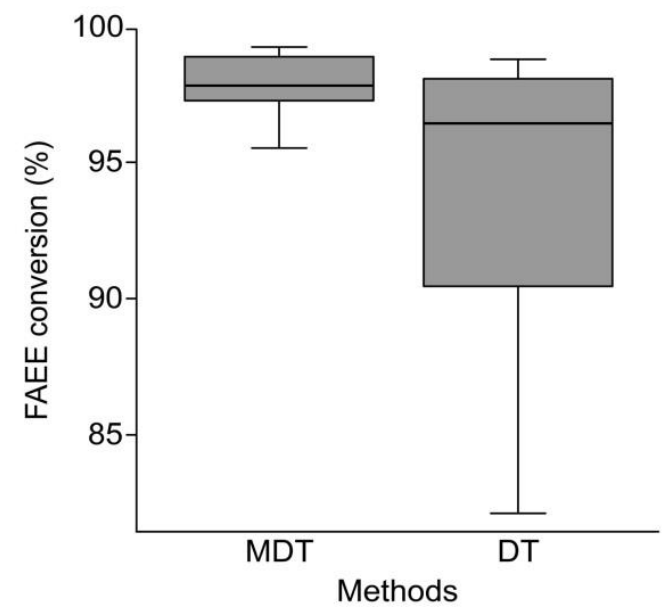

Figure 1. Distribution of FAEE conversion yield using the reference direct transesterification (DT) and proposed microscale direct transesterification (MDT) methods. Comparison of means, standard errors and standard deviations of FAEE conversion in both methods show that both averages are similar, but the microscale method has a lower deviation.

The use of ethanol instead of methanol for transesterification is inherently safer because the vapor pressure of ethanol is lower than that of ethanol. Also, ethanol is less polar than methanol, enhancing lipid solubility in ethanol. One important detail of direct 
transesterification with ethanol is that this alcohol incorporates an extra methylidene group $\left(-\mathrm{CH}_{2}-\right)$ compared with a methyl ester. Therefore, the fatty acid content will be overestimated by about $4.7 \%$ for a typical 18 -carbon fatty acid, if the FAME is used as analytical reference (molar mass of the FAEE is 312 while the FAME is $298 \mathrm{~g} / \mathrm{mol}$ ). If a FAEE mixture is used as reference, there is no need for correction for the values. Fatty acids with 16 to 18 carbons comprise most of the typical plant and microbial oils[30].

For the seven microorganisms tested in this study, FAEE was routinely recovered at more than $90 \%$ yield in the proposed microscale method, indicating that the ethanolysis process described herein is a robust procedure. The fatty acid conversion differences between the two procedures averaged $4.4 \%$. The compositions of the obtained fatty acids using the two methods were virtually identical for all samples, and the proposed method recovered higher amounts of nearly all identified fatty acids; therefore, the estimates of fatty acid content were equivalent for both procedures, with a lower error for the microscale method.
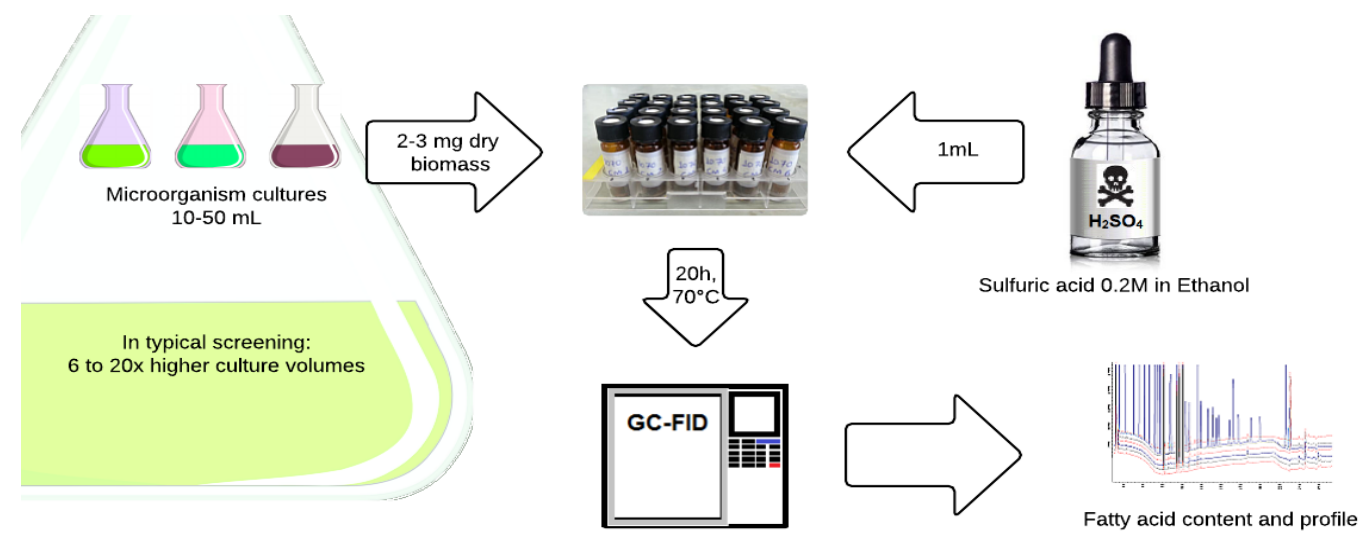

Figure 2. Overview of the method. The low amount of biomass means that low culture volumes can be used -6 to 20 times lower than the typical volume needed for biomass generation

Figure 2 shows the overall rationale behind the method. No significant differences in the conversion of TAGs were observed related to lipid content. This finding contrasts with previous reports [12] that showed significantly decreased conversion in microscale. The microscale method proved to be simple and reliable and may be applied in the screening of several kinds of microbial biomass, such as microalgae and yeast. This is especially important considering that the low amount of biomass needed $(3 \mathrm{mg})$ can be obtained from low culture volumes (10 to 50 milliliters for typical microalgal cultures). Therefore, several candidate microorganisms can be cultivated and assayed in parallel, in small scale. The effective use of ethanol also points to the possibility of industrial direct transesterification for nutraceutical, cosmetic and fuel ethyl fatty acid esters.

\section{CONCLUSION}

The microscale direct transesterification of microbial biomass can be achieved with low amounts of dry biomass and dehydrated acidified ethanol. High yields, above $96 \%$, are reached. The solvent extraction of FAEE from the reaction medium, and its use in GC analysis is accurate and reliable. This method is also inherently safer due to the use of ethanol, which has a lower vapor pressure, and is simpler to implement than traditional transesterification methods using prior extraction. The method is especially useful for the parallel screening of microorganisms based on its lipid content, because of the use of small culture volumes (10 to 50 milliliters), so as to obtain $2-3 \mathrm{mg}$ of dry biomass. The method is, therefore, practical for screening of lipid-producing microorganisms, such as microalgae and yeasts. 
Funding: This research was funded by CNPq, grant number 407543/2013-0, and CAPES PROEXprogram.

Conflicts of Interest: The authors declare no conflict of interest. The funders had no role in the design of the study; in the collection, analyses, or interpretation of data; in the writing of the manuscript, or in the decision to publish the results.

\section{REFERENCES}

1. Naik SN, Goud V V, Rout PK, Dalai AK. Production of first and second generation biofuels: a comprehensive review. Renew. Sustain. Energy Rev. Elsevier; 2010;14:578-97.

2. Cheng JJ, Timilsina GR. Status and barriers of advanced biofuel technologies: A review. Renew. Energy. Elsevier; 2011;36:3541-9.

3. Pardo $\mathrm{Y}$, Sánchez E, Kafarov V. Life cycle assessment of third generation biofuels production. Chem. Eng. Trans. 2010;21:1177-82.

4. González A, Kafarov V. Design of a multifunctional reactor for third generation biofuels production. Chem. Eng. 2010;21.

5. Chisti Y. Biodiesel from microalgae. Biotechnol. Adv. Elsevier; 2007;25:294-306.

6. Finco AM de O, Mamani LDG, Carvalho JC de, de Melo Pereira GV, Thomaz-Soccol V, Soccol CR. Technological trends and market perspectives for production of microbial oils rich in omega-3. Crit. Rev. Biotechnol. [Internet]. 2016 [cited 2016 Nov 8];8551:1-16. Available from: http://www.tandfonline.com/doi/abs/10.1080/07388551.2016.1213221

7. Mutanda T, Ramesh D, Karthikeyan S, Kumari S, Anandraj A, Bux F. Bioprospecting for hyper-lipid producing microalgal strains for sustainable biofuel production. Bioresour. Technol. [Internet]. 2011 [cited 2016 Mar 31];102:57-70. Available from: http://www.scopus.com/inward/record.url?eid=2-s2.0-77957375117\&partnerlD=tZOtx3y1

8. Knothe $G$. Dependence of biodiesel fuel properties on the structure of fatty acid alkyl esters. Fuel Process. Technol. Elsevier; 2005;86:1059-70.

9. Makareviciene V, Janulis P. Environmental effect of rapeseed oil ethyl ester. Renew. Energy. 2003;28:2395-403.

10. VICENTE G, MARTINEZ M, ARACIL J. Optimisation of integrated biodiesel production. Part I. A study of the biodiesel purity and yield. Bioresour. Technol. 2007;98:1724-33.

11. Chen L, Liu T, Zhang W, Chen X, Wang J. Biodiesel production from algae oil high in free fatty acids by two-step catalytic conversion. Bioresour. Technol. Elsevier; 2012;111:208-14.

12. Tran D-T, Chen C-L, Chang J-S. Effect of solvents and oil content on direct transesterification of wet oil-bearing microalgal biomass of Chlorella vulgaris ESP-31 for biodiesel synthesis using immobilized lipase as the biocatalyst. Bioresour. Technol. Elsevier; 2013;135:213-21.

13. Johnson MB, Wen Z. Production of biodiesel fuel from the microalga Schizochytrium limacinum by direct transesterification of algal biomass. Energy \& Fuels. ACS Publications; 2009;23:5179-83.

14. Ehimen EA, Sun Z, Carrington GC. Use of ultrasound and co-solvents to improve the in-situ transesterification of microalgae biomass. Procedia Environ. Sci. Elsevier; 2012;15:47-55.

15. Liu B, Zhao ZK. Biodiesel production by direct methanolysis of oleaginous microbial biomass. J. Chem. Technol. Biotechnol. Wiley Online Library; 2007;82:775-80.

16. Wahlen BD, Willis RM, Seefeldt LC. Biodiesel production by simultaneous extraction and conversion of total lipids from microalgae, cyanobacteria, and wild mixed-cultures. Bioresour. Technol. Elsevier; 2011;102:2724-30. 
17. Koberg $M$, Cohen $M$, Ben-Amotz A, Gedanken A. Bio-diesel production directly from the microalgae biomass of Nannochloropsis by microwave and ultrasound radiation. Bioresour. Technol. Elsevier; 2011;102:4265-9.

18. Haas MJ, Scott KM, Marmer WN, Foglia TA. In situ alkaline transesterification: an effective method for the production of fatty acid esters from vegetable oils. J. Am. Oil Chem. Soc. Springer; 2004;81:83-9.

19. Demirbaş A. Biodiesel fuels from vegetable oils via catalytic and non-catalytic supercritical alcohol transesterifications and other methods: a survey. Energy Convers. Manag. Elsevier; 2003;44:2093-109.

20. Miao X, Wu Q. Biodiesel production from heterotrophic microalgal oil. Bioresour. Technol. Elsevier; 2006;97:841-6.

21. Özgül-Yücel S, Türkay S. FA monoalkylesters from rice bran oil by in situ esterification. J. Am. Oil Chem. Soc. Springer; 2003;80:81-4.

22. Tom Tyner Chair AC on AR. Ethyl Alcohol, Absolute. ACS Reag. Chem. [Internet]. American Chemical Society; 2017. Available from: https://doi.org/10.1021/acsreagents.4136

23. Meher LC, Sagar DV, Naik SN. Technical aspects of biodiesel production by transesterification-a review. Renew. Sustain. energy Rev. Elsevier; 2006;10:248-68.

24. Al-Widyan MI, Al-Shyoukh AO. Experimental evaluation of the transesterification of waste palm oil into biodiesel. Bioresour. Technol. Elsevier; 2002;85:253-6.

25. Zhou W, Konar SK, Boocock DGB. Ethyl esters from the single-phase base-catalyzed ethanolysis of vegetable oils. J. Am. Oil Chem. Soc. Springer; 2003;80:367-71.

26. Encinar JM, Gonzalez JF, Rodriguez JJ, Tejedor A. Biodiesel Fuels from Vegetable Oils: Transesterification of Cynara $\mathrm{C}$ ardunculus L. Oils with Ethanol. Energy \& fuels. ACS Publications; 2002;16:443-50.

27. Vicente G, Martınez M, Aracil J. Integrated biodiesel production: a comparison of different homogeneous catalysts systems. Bioresour. Technol. Elsevier; 2004;92:297-305.

28. D'Oca MGM, Viêgas C V, Lemoes JS, Miyasaki EK, Morón-Villarreyes JA, Primel EG, et al. Production of FAMEs from several microalgal lipidic extracts and direct transesterification of the Chlorella pyrenoidosa. biomass and bioenergy. Elsevier; 2011;35:1533-8.

29. Xu H, Miao X, Wu Q. High quality biodiesel production from a microalga Chlorella protothecoides by heterotrophic growth in fermenters. J. Biotechnol. Elsevier; 2006;126:499-507.

30. Christophe G, Kumar V, Nouaille R, Gaudet G, Fontanille P, Pandey A, et al. Recent developments in microbial oils production: a possible alternative to vegetable oils for biodiesel without competition with human food? Brazilian Arch. Biol. Technol. [Internet]. Tecpar; 2012 [cited 2018 Jul 26];55:29-46. Available from: http://www.scielo.br/scielo.php?script=sci_arttext\&pid=S1516-89132012000100004\&lng=en\&tlng=en

(C) 2018 by the authors. Submitted for possible open access publication under the terms and conditions of the Creative Commons Attribution (CC BY NC) license (http://creativecommons.org/licenses/by/4.0/). 